\title{
IRRATIONAL PRESCRIBING OF ANTIBIOTICS FOR VIRAL RESPIRATORY TRACT INFECTIONS IN CHILDREN AGED 1 - 14 YEARS- A STUDY IN RURAL AREA OF CHANDU-BUDHERA
}

\author{
Satya Kiran Kapur1, Yamini2, Harish Gupta3 ${ }^{3}$ Pawan Kumar 4 \\ ${ }^{1}$ Associate Professor, Department of Paediatrics, Faculty of Medicine and Health Sciences, SGT University, Budhera, Gurugram, \\ Haryana. \\ ${ }^{2}$ Professor and HOD, Department of Surgery, SHKM Government Medical College, Nalhar, Nuh, Haryana. \\ ${ }^{3}$ Senior Resident, Department of Paediatrics, Faculty of Medicine and Health Sciences, SGT University, Budhera, Gurugram, Haryana. \\ 4 Junior Resident, Faculty of Medicine and Health Sciences, SGT University, Budhera, Gurugram, Haryana.
}

\section{ABSTRACT}

\section{BACKGROUND}

During the winter season, viral respiratory tract infections are most common amongst children and prescribing of antibiotics has become a routine practice. This study was undertaken to know the extent of irrational prescribing of antibiotics by General Practitioners (GPs) and Practicing Paediatricians (PPs) for viral respiratory tract infections in children.

\section{MATERIALS AND METHODS}

The study was done from 15.11.2016 to 15.03.2017 (Winter season) in the Paediatric OPD of SGT Hospital, Faculty of Medicine and Health Sciences, SGT University, Budhera, Gurugram (Gurgaon). Children aged 1 - 14 years who attended the Paediatric OPD and were prescribed antibiotics for viral respiratory tract infections by the General Practitioners as well as by Practicing Paediatricians before visiting the SGT Hospital were included in the study.

\section{RESULTS}

The most common symptoms in children aged 1 - 14 years in viral respiratory infections were sore throat, cough, runny nose, sneezing and fever, for which antibiotics were prescribed by General Practitioners as well as by Practicing Paediatricians. The most common prescribed antibiotics were penicillins (80.30\%) followed by cephalosporins $(15.12 \%)$.

\section{CONCLUSION}

Antibiotics are frequently and irrationally prescribed for viral respiratory tract infections despite their non-recommendations according to standardised guidelines.

\section{KEYWORDS}

Paediatric Outpatients, Viral Respiratory Tract Infections, Antibiotics, Irrational Prescribing.

HOW TO CITE THIS ARTICLE: Kapur SK, Yamini, Gupta H, et al. Irrational prescribing of antibiotics for viral respiratory tract infections in children aged 1 - 14 years- a study in rural area of Chandu-Budhera. J. Evolution Med. Dent. Sci. 2017;6(51):39223925, DOI: $10.14260 / J e m d s / 2017 / 848$

\section{BACKGROUND \\ Acute respiratory tract infections are one of the most common childhood infections in Paediatric OPDs during the winter season. ${ }^{[1]}$ The prescribing of antibiotics has become a routine practice for treating acute respiratory tract infections. ${ }^{[2]}$ The upper respiratory tract infections account for $57 \%$ of the antibiotics used with a further $30 \%$ for lower respiratory tract infections. [3] Numerous studies have shown widespread unnecessary use of antimicrobials in patients with viral respiratory tract infections. ${ }^{[4,5]}$ In a study reported by Steinke et al, non-training practices in Tayside, UK were in general found to prescribe significantly more antibiotics as well as a higher proportion of broad-spectrum penicillins, a higher proportion of newer antibiotics and a greater number of different antibiotics per doctor compared to training}

Financial or Other, Competing Interest: None.

Submission 22-05-2017, Peer Review 15-06-2017,

Acceptance 20-06-2017, Published 24-06-2017.

Corresponding Author:

Dr. Satya Kiran Kapur

H- 40, First Floor,

Residency Greens (Opposite Unitech Cyber Park) Sector 46,

Gurugram (Gurgaon)-122003,

Haryana, India.

E-mail: kapoorsatyakiran@gmail.com

DOI: $10.14260 /$ jemds $/ 2017 / 848$ practices.[6] Irrational or inappropriate use of drugs is described by James Trostle as consumption of drugs in a situation where they are unlikely to have the desired effect.[7] Guidelines have been propagated for rational use of antibiotics. Rational use implies using an antibiotic only when indicated, choosing a cost-effective agent which provides appropriate antimicrobial coverage for the diagnosis that is suspected and prescribing the optimal dose and duration of the antimicrobial. The WHO Global Strategy for Containment of Antimicrobial Resistance defines the appropriate use of antimicrobials as the cost-effective use which maximises clinical therapeutic effect, while minimising both drug-related toxicity and the development of antimicrobial resistance (http://www.who.int/ drug resistance/ WHO_Strategy_ English. pdf).

\section{Objective}

The study was conducted on patients who attended Paediatric OPD of SGT Hospital, Faculty of Medicine and Health Sciences, SGT University, Budhera, Gurgaon, to know the extent of irrational prescribing of antibiotics to children suffering from acute respiratory tract infections by General Practitioners as well as by Practicing Specialists. 


\section{MATERIALS AND METHODS}

The study was done from 15.11.2016 to 15.03.2017 (winter season) in the Paediatric OPD of SGT Hospital, Faculty of Medicine and Health Sciences, SGT University, Budhera, Gurgaon. Patients of either sex at age group between 1 - 14 years who attended the Paediatric OPD and were prescribed antibiotics for respiratory tract infections by General Practitioners as well as by Practicing Paediatricians before visiting SGT Hospital, were included in the study to know the extent of rational/irrational use of antibiotics. Rational use of antibiotics is defined as using an antibiotic only when indicated, providing appropriate antimicrobial coverage for the suspected diagnosis, in optimal dose and duration to treat the disease. Indications for prescribing antibiotics become rational when bacterial infections are suspected. In bacterial respiratory tract infections, the patient's main complaints are high-grade fever, purulent nasal discharge, cough which produces phlegm and the investigations show increase in total leucocyte count ( $>11000$ cells/cumm), increased polymorphs $(>60 \%)$ in differential leucocyte count, swabs taken from nasal secretions and throat are positive for bacterial growth and chest x-ray shows infiltrations or consolidation or pleural effusion. Data regarding age, sex, diagnosis, drug details which included name of the drug (generic/brand name), dosage form, dose frequency and duration were recorded in specially designed data entry forms. Wherever possible, acquired data was compared against National guideline-based medicines, major antibiotic guidelines recommended by World Health Organisation (WHO) ${ }^{[8]}$ and American Academy of Paediatrics (AAP) ${ }^{[9]}$ and cross-referenced against Cochrane studies.

\section{Exclusion Criteria}

- Children having respiratory distress.

- Children suffering from chronic cough.

- Children having history of contact with persons suffering from tuberculosis.

- Sick looking patients.

Patients requiring indoor admission. Most of the upper respiratory tract infections are viral in origin. A report by World Health Organisation (WHO) indicates that for every 100 respiratory infection incidences, only 20 require antibiotic treatment.[10] In patients diagnosed by General Practitioners (GPs) and Practicing Paediatricians (PPs) as sore throat, main complaints were scratchy sensation in the throat, pain during swallowing, hoarseness of voice, lowgrade fever and cough. In our study, Investigations done were complete blood count and the throat swabs to detect bacterial growth. In patients diagnosed by GPs and PPs as acute bronchitis, main complaints were cough, low-grade fever and wheezing. In our study, Investigations done were complete blood count and chest x-ray. In patients diagnosed by GPs and PPs as common cold, main complaints were nasal congestion, sneezing, runny nose and mild cough. In our study, Investigations done were complete blood count and swabs from nasal secretions to detect bacterial growth. In patients diagnosed by GPs and PPs as Pneumonia, main complaints were fever, cough and fatigue. In our study, Investigations done were complete blood count and chest $\mathrm{x}$-ray.

\section{RESULTS}

A total of 4012 paediatric patients who suffered from respiratory tract infections and were prescribed antibiotics by GPs as well as PPs before visiting SGT Hospital were included in the study conducted from 15.11.2016 to 15.03.2017 (Winter season) when respiratory tract infections are most common. Out of 4012 patients, 2326 were male children and 1686 were female children. The most common presenting symptoms were sore throat, cough, runny nose, sneezing and fever.

\begin{tabular}{|c|c|c|}
\hline Age (Years) & Number of Patients & $\mathbf{\%}$ \\
\hline $1-3$ & 1404 & 35 \\
\hline $3-6$ & 1805 & 45 \\
\hline $6-14$ & 803 & 20 \\
\hline Sex & 2326 & 58 \\
\hline Male & 1686 & 42 \\
\hline Female & Sex \\
\hline \multicolumn{2}{|c|}{ Table 1. Paediatric Outpatients with Respect to Age and } \\
\hline
\end{tabular}

1 - 3 yrs., 3 - 6 yrs., 6 - 14 yrs.

\begin{tabular}{|c|c|c|c|c|c|c|c|c|}
\hline Diagnosis & M & F & M & F & M & F & Total & \% \\
\hline Sore throat & 564 & 426 & 752 & 523 & 372 & 176 & 2813 & 70.11 \\
\hline Acute bronchitis & 167 & 118 & 210 & 161 & 125 & 52 & 833 & 20.76 \\
\hline Common cold & 65 & 36 & 81 & 57 & 43 & 25 & 307 & 7.65 \\
\hline Pneumonia & 16 & 12 & 11 & 10 & 7 & 3 & 59 & 1.47 \\
\hline
\end{tabular}

Table 2. Diagnosis of Antibiotic prescribing in Paediatric Outpatients with Respect to Age and Sex

The most common diagnosis of antibiotic prescribing in paediatric outpatients was sore throat $(70.11 \%)$, followed by acute bronchitis $(20.76 \%)$ and the common cold (7.65).

\begin{tabular}{|c|c|c|}
\hline Antibiotics Prescribed & Total Number & $\mathbf{\%}$ \\
\hline Penicillins & & \\
\hline Amoxicillin, Clavulanic acid & 2324 & 57.92 \\
\hline Amoxicillin & 898 & 22.38 \\
\hline Cephalosporins & & \\
\hline Cefpodoxime & 431 & 10.74 \\
\hline Cefixime & 176 & 4.38 \\
\hline Macrolides & 183 & \\
\hline Azithromycin & 4.56 \\
\hline Table 3. Antibiotics prescribed for Various Diagnoses \\
\hline
\end{tabular}

The penicillin class of antibiotics (Amoxicillin, Clavulanic acid; Amoxicillin) remains the most frequently prescribed followed by Cephalosporins (Cefpodoxime Proxetil and Cefixime).

\begin{tabular}{|c|c|c|}
\hline & Number of Patients & \% \\
\hline Syrups & 3763 & 93.79 \\
\hline Tablets & 182 & 4.53 \\
\hline Capsules & 67 & 1.66 \\
\hline \multicolumn{2}{|c|}{ Table 4. Dosage Forms Used } \\
\hline
\end{tabular}

Syrups were the common dosage forms (93.79\%) prescribed for all outpatients in paediatric age group. 


\begin{tabular}{|c|c|c|c|c|}
\hline $\begin{array}{c}\text { Prescribed } \\
\text { Antibiotics }\end{array}$ & $\begin{array}{c}\text { Sore } \\
\text { Throat No. } \\
(\%)\end{array}$ & $\begin{array}{c}\text { Acute } \\
\text { Bronchitis } \\
\text { No. (\%) }\end{array}$ & $\begin{array}{c}\text { Common } \\
\text { Cold } \\
\text { No. (\%) }\end{array}$ & $\begin{array}{c}\text { Pneumonia } \\
\text { No. (\%) }\end{array}$ \\
\hline $\begin{array}{c}\text { Amoxicillin, } \\
\text { Clavulanic acid }\end{array}$ & $\begin{array}{c}1686 \\
(59.93)\end{array}$ & $\begin{array}{c}435 \\
(52.22)\end{array}$ & $\begin{array}{c}177 \\
(57.65)\end{array}$ & $\begin{array}{c}26 \\
(44.06)\end{array}$ \\
\hline Amoxicillin & 619 & 207 & 65 & 7 \\
& $(22.00)$ & $(24.84)$ & $(21.17)$ & $(11.86)$ \\
\hline Cefpodoxime & 273 & 112 & 32 & 14 \\
& $(9.70)$ & $(13.44)$ & $(10.42)$ & $(23.72)$ \\
\hline Cefixime & 98 & 52 & 21 & 5 \\
& $(3.48)$ & $(6.24)$ & $(6.84)$ & $(8.47)$ \\
\hline Azithromycin & 137 & 27 & 12 & 7 \\
& $(4.87)$ & $(3.24)$ & $(3.90)$ & $(11.86)$ \\
\hline
\end{tabular}

Table 5. Paediatric Diagnosis and Antibiotics Prescribed

\begin{tabular}{|c|c|c|c|}
\hline Diagnosis & $\begin{array}{c}\text { Total } \\
\text { No. }\end{array}$ & $\begin{array}{c}\text { Rational Use } \\
\text { No. (\%) }\end{array}$ & $\begin{array}{c}\text { Irrational Use } \\
\text { No. (\%) }\end{array}$ \\
\hline Sore Throat & 2813 & $197(7)$ & $2616(93)$ \\
\hline Acute Bronchitis & 833 & $50(6)$ & $783(94)$ \\
\hline Common Cold & 307 & $0(0)$ & $307(100)$ \\
\hline Pneumonia & 59 & $7(12)$ & $52(88)$ \\
\hline \multicolumn{3}{|c|}{ Table 6. Rational/Irrational use of Antibiotics } \\
in Various Diagnoses \\
\hline
\end{tabular}

In viral respiratory tract infections, the main complaints of patients are scratchy sensation in the throat, low-grade fever, sneezing, runny nose and cough. Investigations such as complete blood count shows Total Leucocyte Count (TLC) and Differential Leucocyte Count (DLC) in normal range. Swabs taken from nasal secretions and throat show no bacterial growth. Chest x-ray findings are normal. In our study, out of total 4012 patients, complete blood count in 3290 (82\%) patients showed TLC $(4000-11000$ cells/cumm) and DLC (polymorphs 40 - 60\%, Lymphocytes $20-40 \%$, Monocytes 2 - 8\%, Eosinophils $1-4 \%$, Basophils $0.5-1 \%)$ in normal range. In $722(18 \%)$ patients, TLC was increased ( $>11000$ cells/cumm) and DLC showed increase in polymorphs ( $>60 \%$ ). Throat swabs taken in 2813 patients of sore throat showed no bacterial growth in 2616 (93\%) patients. These patients had TLC and DLC in normal range. So, antibiotics were not indicated in these patients. In 197 (7\%) patients, throat swabs were positive for bacterial growth (Streptococcus). These patients also had increased TLC (> 11000 cells/cumm) and increased polymorphs (> 60\%) in DLC. As antibiotic was indicated in them and Amoxicillin being recommended antibiotic according to guidelines of WHO [8] and AAP [9], Amoxicillin (50 mg/ $\mathrm{kg} /$ day) in three divided doses was prescribed for 5 days. In 833 patients of suspected acute bronchitis, chest x-ray findings were normal in $783(94 \%)$ of patients. These patients had TLC and DLC in normal range. So, antibiotics were not indicated in these patients. In $50(6 \%)$ patients, chest $\mathrm{x}$-ray showed increased bronchovascular markings. These patients also had increased TLC ( $>11000$ cells/cumm) and increased polymorphs ( $>$ $60 \%)$ in DLC. As antibiotic was indicated in them and Amoxicillin being recommended antibiotic according to guidelines of WHO [8] and AAP [9], Amoxicillin (50 $\mathrm{mg} / \mathrm{kg} /$ day) in three divided doses was prescribed for 7 days.

In 307 patients of common cold, swabs taken from nasal secretions showed no bacterial growth. TLC and DLC in these patients were in normal range. So, antibiotics were not indicated in these patients. In 59 patients of suspected Pneumonia, chest $\mathrm{x}$-ray was normal in $52(88 \%)$ patients. TLC and DLC were also in normal range. So, antibiotics were not indicated in these patients. In $7(12 \%)$ patients, chest x-ray showed small patch of consolidation. In these patients, TLC was increased ( $>11000$ cells/cumm) and DLC showed increased polymorphs $(>60 \%)$. As antibiotics were indicated in these patients, a combination of Amoxicillin-Clavulanic acid ( $40 \mathrm{mg} / \mathrm{kg} /$ day) in three divided doses was prescribed for 10 days according to guidelines of $\mathrm{WHO}^{[8]}$ and AAP. ${ }^{[9]}$ Patients in which clinical manifestations were scratchy sensation in the throat, low-grade fever, sneezing, runny nose and cough; and investigations such as TLC and DLC were in normal range, swabs from nasal secretions and throat swabs showed no bacterial growth and $\mathrm{x}$-ray findings were normal were of viral origin, because viral respiratory tract infections manifest such symptoms and investigations. As antibiotics were not indicated in viral infections, these patients were prescribed symptomatic treatment in the form of Paracetamol, Chlorpheniramine maleate along with counselling. Followup was done after 7 days. The patients with suspected viral respiratory tract infections got relief with symptomatic treatment. The patients in whom TLC was increased ( $>11000$ cells/cumm), DLC showed increased polymorphs ( $>60 \%$ ), throat swabs showed bacterial growth, chest x-ray showed increased bronchovascular markings/ consolidation, antibiotics (Amoxicillin in patients of Sore throat and Acute bronchitis; a combination of Amoxicillin, Clavulanic acid in patients of Pneumonia) were indicated as per guidelines of $\mathrm{WHO}^{[8]}$ and AAP. ${ }^{[9]}$ On followup examination of these patients after 10 days TLC and DLC were in normal range, throat swabs showed no bacterial growth and chest $\mathrm{x}$ rays were normal.

\section{DISCUSSION}

In this study, the most common diagnosis of antibiotic prescribing in paediatric outpatients was sore throat (70.11\%) followed by acute bronchitis (20.76\%), common cold (7.65\%) and pneumonia (1.47\%). According to Murphy et al, most common causes of antibiotic prescribing are due to respiratory complaints.[11]

The National Institute for Health and Clinical Excellence (NICE) guidelines recommended either delayed or no prescribing for five common diagnoses- acute otitis media, acute sore throat, acute cough/bronchitis, acute sinusitis and common cold.[12] In this study penicillins, cephalosporins and macrolides were prescribed by General Practitioners and Practicing Paediatricians for sore throat, acute bronchitis, common cold and pneumonia.

According to the guidelines recommended by the World Health Organisation ${ }^{[8]}$ and American Academy of Pediatrics, ${ }^{[9]}$ antimicrobial therapy is not recommended in these cases as most of these are of viral origin and self-limiting. Patients in whom symptoms were sore throat, sneezing, runny nose, cough and low-grade fever were suggestive of viral origin and investigations such as TLC and DLC showing normal range, swabs from nasal secretions and throat showing no bacterial growth and chest $\mathrm{x}$-ray with normal findings were suggestive of viral origin and were prescribed symptomatic treatment along with counselling. On followup after 7 days these patients became asymptomatic, thereby confirming that in 2616 out of 2813 (93\%) patients of sore throat 783 out of $833(94 \%)$ patients of acute bronchitis, 307 (100\%) patients of common cold and 52 out of 59 (88\%) patients of pneumonia, antibiotics were prescribed irrationally by practitioners. 
There are several factors other than the clinical condition that could have influenced antibiotic prescription. Such factors include lack of certainty of diagnosis,[13] fear for not treating a bacterial infection, inadequate time for each patient,[14,15] not knowing about the guidelines for prescribing antibiotics and fear of possible litigation.[16]

\section{CONCLUSION}

Antibiotics are frequently and irrationally prescribed for viral respiratory tract infections such as sore throat, acute bronchitis, common cold, etc. despite their nonrecommendations according to the standardised guidelines. This study confirms the irrational prescription of antibiotics for these common conditions in paediatric outpatients.

\section{Abbreviations}

General Practitioners (GPs); Practicing Paediatricians (PPs); World Health Organisation (WHO); American Academy of Paediatrics (AAP); Total Leucocyte Count (TLC); Differential Leucocyte Count (DLC).

\section{REFERENCES}

[1] Arulmoli SK, Sivachandiran S, Perera BJC. Prescribing patterns of antibiotics for children before admission to a paediatric Wardin Jaffna teaching hospital, Sri Lanka. J Child Health 2009;38;121-3.

[2] Bharathiraja R, Sridharan S, Chelliah LR, et al. Factors affecting antibiotic prescribing pattern in paediatric practice. Indian J Paediatric 2005;72(10):877-80.

[3] van der Velden A, Duerden MG, Bell J, et al. Prescriber and patient responsibilities in treatment of acute respiratory tract infections-essential for conservation of antibiotics. Antibiotics (Basel) 2013;2(2):316-27.

[4] Gaur AH, Hare ME, Shorr RI. Provider and practice characteristics associated with antibiotic use in children with presumed viral respiratory tract infections. Pediatrics 2005;115(3):635-41.

[5] Nyquist AC, Gonzales R, Steiner JF, et al. Antibiotic prescribing for children with colds, upper respiratory tract infections, and bronchitis. JAMA 1998;279(11): 875-7.
[6] Steinke DT, Bain DJ, MacDonald TM, et al. Practice factors that influence antibiotic prescribing in general practice in Tayside. J Antimicrobe Chemother 2000;46(3):509-12.

[7] Trostle J. Inappropriate distribution of medicines by professionals in developing countries. Soc Sci Med 1996;42(8):1117-20.

[8] Pocket book of hospital care for children: Guidelines for the management of common Childhood Illnesses. $2^{\text {nd }}$ edn. Geneva: World Health Organization, 2013.

[9] Hersh AL, Jackson MA, Hicks LA, et al. Principles of judicious antibiotic prescribing for bacterial upper respiratory. Pediatrics 2013;132:1146-54.

[10] WHO report on infectious disease: overcoming antimicrobial resistance. Geneva: WHO, 2000. www.int/infectious-disease-report/2000.

[11] Murphy M, Bradley CP, Byrne S. Antibiotic prescribing in primary care, adherence to guidelines and unnecessary prescribing - an Irish perspective. BMC Fam Pract 2012;13:43.

[12] Centre for Clinical Practice at NICE (UK). Respiratory tract infections-antibiotic prescribing: prescribing of antibiotics for self-limiting respiratory tract infections in adults and children in primary care. National Institute for Health and Clinical Excellence London, (UK): NICE Clinical Guidelines, No. 69), 2008.

[13] MacFarlane J, Lewis SA, MacFarlane $R$, et al. Contemporary use of antibiotics in 1089 adults presenting with acute lower respiratory tract illness in general practice in the UK: implications for developing management guidelines. Resp Med 1997;91(7):427-34.

[14] Bain J. Childhood otalgia: acute otitis media. 2. Justification for antibiotic use in general practice. BM] 1990;300(6730):1006-7.

[15] Butler CC, Rollnick S, Pill R, et al. Understanding the culture of prescribing: qualitative study of general practitioners' and patients' perceptions of antibiotics for sore throats. BMJ 1998;317:637-42.

[16] Fidler DP. Legal issues associated with antimicrobial drug resistance. Emerg Infect Dis 1998;4(2):169-77. 